\title{
Effect of Rising Temperature Stress on Growth and Physiology of Domestic Crops of Rajasthan, India
}

\author{
Divya Sharma ${ }^{1}$, Hrish Kumar Rachhoya ${ }^{2 *}$, Mukesh Sharma ${ }^{2}$ and Ranjana Agarwal $^{3}$ \\ ${ }^{1}$ Kanoria PG Mahila Mahavidyalaya, Jaipur, India \\ ${ }^{2}$ Krishi Vigyan Kendra, (GVM), Sardarshahar, District-Churu -1, India \\ ${ }^{3}$ Department of Biotechnology, Kanoria PG Mahila Mahavidyalaya, \\ Jaipur (Rajasthan) India, India \\ *Corresponding author
}

\section{Keywords}

Antioxidants, Heat stress, Proline, ROS, Wheat

Article Info

Accepted:

10 June 2018

Available Online:

10 July 2018

\section{A B S T R A C T}

A developed human society in today's era needs advancement in food production and yield to feed the ever blooming monstrous population. The existing feed supply resources are however confronted with a variety of environmental complexities like the global warming, curtailment of the agricultural lands and deterioration of the resources supporting the crop production. Abiotic stress like heat, cold, drought, flood, heavy metal etc create unfavourable condition for crop plant which effect its growth, survival and reproduction. These abiotic stresses induce various adaptive, biochemical and physiological responses in plants in order to preserve their homeostatic equilibrium. Abiotic stresses also exert substantial effects on the production of several bioactive compounds in plants and cause the increases in the level of sugars, soluble proteins, antioxidant enzymes, proline, chlorophyll, the appearance of new isoforms of protein and change in membrane lipid composition. The present study aims at studying the effect of heat stress on wheat varieties and their mechanisms to combat the stress. Five varieties of crops namely Wheat (Lok-1, Raj.4120, Raj.4037, Raj 3765 and DBW-90), Mustard (Pusa Bold, Pusa Jai Kisan, RH 0749), Chickpea (Pratap Chana, GNG-1581), Mung (JPM-0203C/SI), and Soyabean (JP-95-60) were taken. These were grown on MS media and high temperature was levied after the appearance of plantlets for continuous five days. The plantlets were excised after 15 days of inoculation for further analysis. Different morphological parameters including shoot-root height and weight were measured. The heat stress caused specific changes in the biochemical potential of the plant and was measured by observing the chlorophyll amounts, antioxidants including Peroxidase (POX), Ascorbate peroxidase (APX) and polyphenol peroxidase (PPO) enzyme activities and also ospmoprotectants like proline. Morphological studies revealed best performance of Raj 4037 and Raj 3765 varieties under high temperature. A significant increase in the antioxidative enzyme activity was also noted in these varieties. The MDA and proline content was significantly high in these varieties after stress application suggesting that they are better suited to combat the oxidative stress injury amongst all varieties. The study concluded that Raj 4037 and Raj 3765 varieties of wheat, Pusa Jai Kisan of mustard and GNG-1581 of gram were best suitable for the Rajasthan in the increasing intricacy of global temperature rise. Amongst soyabean and mung, Soyabean in better adapted to grow under higher temperatures. A developed human society in today's era needs advancement in food production and yield to feed the ever blooming monstrous population. The existing feed supply resources are however confronted with a variety of environmental complexities like the global warming, curtailment of the agricultural lands and deterioration of the resources supporting the crop production. Abiotic stress like heat, cold, drought, flood, heavy metal etc create unfavourable condition for crop plant which effect its growth, survival and reproduction. These abiotic stresses induce various adaptive, biochemical and physiological responses in plants in order to preserve their homeostatic equilibrium. Abiotic stresses also exert substantial effects on the production of several bioactive compounds in plants and cause the increases in the level of sugars, soluble proteins, antioxidant enzymes, proline, chlorophyll, the appearance of new isoforms of protein and change in membrane lipid composition. The present study aims at studying the effect of heat stress on wheat varieties and their mechanisms to combat the stress. Five varieties of wheat (Lok-1, Raj.4120, Raj.4037, Raj 3765 and DBW-90) were taken. These were grown on MS media and high temperature was levied after the appearance of plantlets for continuous five days. The plantlets were excised after 15 days of inoculation for further analysis. Different morphological parameters including shoot-root height and weight were measured. The heat stress caused specific changes in the biochemical potential of the plant and was measured by observing the chlorophyll amounts, antioxidants including Peroxidase (POX), Ascorbate peroxidase (APX) and polyphenol peroxidase (PPO) enzyme activities and also ospmoprotectants like proline. Morphological studies revealed best performance of Raj 4037 and Raj 3765 varieties under high temperature. A significant increase in the ant oxidative enzyme activity was also noted in these varieties. The MDA and proline content was significantly high in these varieties after stress application suggesting that they are better suited to combat the oxidative stress injury amongst all varieties. The study concluded that Raj 4037 and Raj 3765 varieties were best suitable for the Rajasthan in the increasing intricacy of global temperature rise. 


\section{Introduction}

Every species has a range of temperature to which it is tolerant and represented in a minimum, maximum and optimum range and this temperature range affect the plant growth and development. The summarization of these values was given by Hatfield et al., (2008, 2009) for different species of grains. According to Intergovernmental Panel Climate Change (IPCC) 2007, the temperature change was expected to be in range of $2-3^{\circ} \mathrm{C}$ for upcoming 30-50 years. Changes in climatic conditions are also correlated at regional scale for various stresses (Kao and Ganguly, 2011). The increase in global temperature has caused erratic weather patterns and is affecting human life, wildlife, vegetation and sea level. Currently, the increased global temperature has been caused mainly by the high emission of green house gases, urbanization, cutting of trees and imbalance of ecosystem. An analysis of annual and seasonal temperature trends in the country from 1901 and 2017, indicate that the country has been getting warmer continuously, consistently and rapidly. Abiotic stress like heat, cold, drought, flood, heavy metal etc is unfavourable condition for crop plant which affects its growth, survival and reproduction. The various climatic calamities like temperature and drought are major key challenges in global agricultural production (Mittler and Blumwald, 2010).

Plants because of their sessile nature are unable to move in response to the unfavourable changes in the habitat. Therefore, to cope up with stress condition plants have evolved complex adaptation which has been primarily considered for cereal improvement strategies. Although stress tolerance mechanisms vary from species to species, basic cellular response to abiotic stresses appears to be conserved among all plants (Chinnusamy et al., 2005). These abiotic stresses induce various adaptive, biochemical and physiological responses in plants in order to preserve their homeostatic equilibrium (Peleg and Blumwald, 2011). Abiotic stresses also exert substantial effects on the production of several bioactive compounds in plants (Azhar et al., 2011). The communication of plants with these abiotic stresses affects the plant's biochemical nature by changing polypeptide, enzymes and metabolites. It increase the levels of sugars, soluble proteins, antioxidant enzymes, proline, chlorophyll, the appearance of new isoforms of protein and change in membrane lipid composition (Azymi et al., 2012). Stressinduced morphogenic responses (SIMRs) comprise alterations in cell division and elongation (Potters et al., 2007, 2009). The direct effects of high temperature stress depend on the crop species and its adaptability (Hasanuzzaman et al., 2012). Seed germination and seedling growth rates including yield, quality, and safety are reduced at a very rapid rate (Hasanuzzamanet.al 2013). Heat typically causes a reversible loss in PS-II functionality, which is reflected by changes in the chlorophyll fluorescence parameter Fv/Fm, and indicates that heat reduces photosynthetic capacity (Haque et al. 2014). The tendency of some wheat genotypes to maintain a high chlorophyll content and functionality under heat is a trait that could help to maintain sugar supply and hence high rates of grain filling during heat stress. Therefore the ability to maintain grain weight under heat stress conditions in the field has been found to correlate with the stay-green trait (Talukder et al., 2014). Reactive oxygen species (ROS) are constantly produced in the cells and they function as signals or mediators in different biochemical pathways. ROS generated during oxidative stress at dangerous levels are detrimental to cellular components, like membrane lipids, proteins, and nucleic acids. Various plant species have developed their antioxidant defence mechanisms to combat the drastic effects of abiotic stress. 
ROS defence mechanism comprises of enzymatic and non-enzymatic components. Enzymatic ROS-scavenging system includes peroxidases (POX), catalase (CAT) and glutathione reductase (GR), while the nonenzymatic components include ascorbic acid (ASC) and reduced glutathione (GSH). Elevated levels of $\mathrm{H}_{2} \mathrm{O}_{2}$ and malondialdehyde (MDA) reflect imbalance in ROS production and detoxification. Plants also combat stress induced high osmotic pressure through metabolic adjustments, such as synthesis of osmoprotectant like proline (Zhang et al., 2011). In addition, plants produce a huge number of metabolites as adaptation, to the stress conditions. Among these, metabolites of interest are the carotenoids which are widely distributed in nature. These not only act as accessory pigments for photosynthesis and as precursors to plant hormones, but also impart various benefits to human health (Johnson, 2002).

\section{Objective}

The objective/aim of the present study was to characterize/determine the effect of high temperature stress in 5 major crops along with different varieties of these crops of Rajasthan namely Wheat (Lok-1, Raj.4120, Raj.4037, Raj 3765 and DBW-90), Mustard (Pusa Bold, Pusa Jai Kisan, RH 0749), Chickpea (PratapChana, GNG-1581), Mung (JPM-0203C/SI), and Soyabean (JP-95-60)to asses which variety is more tolerant to high temperature as compared to other variety.

\section{Materials and Methods}

The present study was to characterize/determine the effect of high temperature stress in 5 major crops along with different varieties of these crops of Rajasthan namely Wheat (Lok-1, Raj.4120, Raj.4037, Raj 3765 and DBW-90), Mustard (Pusa Bold, Pusa Jai Kisan, RH 0749), Chickpea (Pratap
Chana, GNG-1581), Mung (JPM-02-03C/SI), and Soyabean (JP-95-60) was grown on MS media.The preparation of MS media was done as per the protocol using the Murashige and Skoog medium (Himedia PT021). It was supplemented with additional 3\% sucrose (Loba chemicals, India) and the gelling agent $0.8 \%$ agar (Bacteriological grade, Merck, India) was added to the media for solidification. 20\% extran (Liquid detergent, Merck, India) was used as washing agent for surface sterilization. Repeated distilled water wash was given to remove excess detergent. The seeds were then taken inside the laminar air flow cabinet and washed with $0.5 \% \mathrm{HgCl}_{2}$ (Merck, India) solution. Autoclaved distilled water was used for repeated washing again. The seeds of the plant were inoculated in the medium containing flasks then transferred on $26 \pm 2^{0} \mathrm{C}$ in incubator. After a period of 1 day, the germinated seedlings containing flasks were kept at different temperatures for a period of 5 hours daily. The germinated seedlings were monitored continuously for their growth and observations were recorded on the tenth and fifteenth day of the inoculation, after which the seedlings were excised from the medium. The plant parts i.e. root and shoot were used for extraction of various ROS scavenging enzymes.

\section{Morphological parameters}

Observations on germination efficiency (\%), fresh and dry weight $(\mathrm{mg})$ of shoots and roots, length $(\mathrm{cm})$ of shoots and roots, root shoot ratio were recorded for each these crops species onfour different concentrations of salinity and drought and the control treatment.

\section{Germination efficiency}

Germination efficiency (\%) was recorded for each crop after 7 days of seedling growth as follows: 
Germination efficiency $(\%)=100 *($ number of seeds germinated/ total number of seeds inoculated). Seeds were considered germinated when the emergent radical reached $2 \mathrm{~mm}$ in length.

\section{Biochemical analysis}

Enzyme assays

\section{Peroxidase enzyme (POX)}

Peroxidase activity (POX) was based upon the Guaiacol $-\mathrm{H}_{2} \mathrm{O}_{2}$ method as described by Racusen and Foote, (1965)

\section{Reagents}

Extraction buffer $(50 \mathrm{mM}$ sodium phosphate buffer, $\mathrm{pH}$ 7.0)

$1 \%$ Guaiacol

$50 \mathrm{mM} \mathrm{H}_{2} \mathrm{O}_{2}$

enzyme extract

\section{Ascorbate Peroxidase (APX)}

Total APX activity was assayed according to Nakano and Asada, (1981).

\section{Reagents}

Extraction buffer $(50 \mathrm{mM}$ sodium phosphate buffer, $\mathrm{pH}$ 7.0)

mM EDTA

$\mathrm{mM} \mathrm{H} \mathrm{H}_{2}$

$0.5 \mathrm{mM}$ Ascorbate

\section{Chlorophyll estimation}

Chlorophyll a, Chlorophyll b, and carotenoids were extracted according to the method of Arnon, (1949).

\section{Lipid peroxidation}

Malondialdehyde (MDA) content was determined as a product of lipid peroxidation in both shoot and root tissues by following Heath and Packer, (1968) method.

\section{Reagents}

Thiobarbituric acid (TBA)

Trichloroacetic Acid (TCA)

\section{Proline}

Determination of Proline content was done according to Bates et al., (1973).

\section{Reagents}

$3 \%$ Sulfosalicyclic acid

Glacial acetic acid (GAA)

Acid ninhydrin (1.2gm ninhydrin in $30 \mathrm{ml}$ GAA $+20 \mathrm{ml}$ orthophosphoric acid)

Toluene

Proline standard $(10 \mathrm{mg} / 100 \mathrm{ml})$

\section{Statistical analysis}

Statistical analysis (Origin 8 and MS Excel) was used for calculations of various observations that were recorded from various experiments.

\section{Results and Discussion}

Temperature stress i.e. deviation from the optimal growth temperature of the plant, often causes negative impacts on plant metabolism, cellular homeostasis, and major physiological processes.

\section{Morphological parameters}

The primary response by plant against any kind of stress is the production of reactive oxygen species. The is the key mechanism against stress and these species later act as secondary messengers which activates stress response and defence pathways via signal transduction (Knight and Knight, 2001).The 
optimal levels of ROS in plants are very low $\left(240 \mu \mathrm{M} \quad \mathrm{s}^{-1} \mathrm{O}_{2}^{-1}\right.$ and $0.5 \mu \mathrm{M} \quad \mathrm{H}_{2} \mathrm{O}_{2}$ in chloroplasts) but these values are enhanced by various stresses upto many folds $\left(720 \mu \mathrm{M} \mathrm{s}^{-1}\right.$ $\mathrm{O}_{2}^{-1}$ and 5-15 $\mu \mathrm{M} \mathrm{H} \mathrm{H}_{2} \mathrm{O}_{2}$ ) (Polle, 2001). Programmed cell death and defense against pathogens are triggered by various levels of stress and ultimately result into enhanced ROS production. The provocation of antioxidant enzymes like superoxide dismutase, catalase, peroxidase is a specific step to detoxify the reactive oxygen species produced by cell organelles like mitochondria, peroxisome and chloroplast (Gill and Tuteja, 2010). In stressful conditions, increased enzyme activity of plant can be correlated with increased stress tolerance. During high and low temperature treatments, many physiological changes occur that result in increased expression of antioxidant enzyme genes to protect from cellular oxidative stress.

In the present study the amounts of chlorophyll varied in the different treatment plants from the control. Amongst wheat varieties, the cultivar Raj 4037 outperforms the others by producing superlative amounts of chlorophyll in heat stressed plantlets as compared to other stressed cultivars. Similarly Pusa Jai kisan in mustard and GNG-1581 cultivar in gram shows better adaptability to heat stress in terms of photosynthetic pigment production as compared to their respective counter cultivars. In all the plant varieties and species, the chlorophyll levels are found to be decreased in the heat stressed condition than their respective controls. Heat stress is known to cause the degradation of photosynthetic pigments which can also be correlated in the present study. The mechanisms by which heat accelerates chlorophyll loss are not known but could be related to damage of thylakoid membranes, which leads to chlorophyll loss and decline in Fv/Fm (Ristic et al., 2007, 2008). Using the chlorophyll fluorescence parameter $\mathrm{O} / \mathrm{P}$ strong positive correlations between losses in PSII functionality and chlorophyll content under heat is observed in both hexaploid and tetraploid wheat. It has been reported that the mechanisms of heataccelerated chlorophyll loss could be related to senescence processes in non stressed plants. Indeed, (Harding et al., 1990), who evaluated various activities in leaves of heat-stressed and nonstressed wheat plants, found that both showed an initial breakdown of thylakoid membranes. They reported that gradual temperature increase induces the chlorophyll formation but at extreme hot conditions its production ceases and similar pattern was also observed in our present study. Our findings correspond to several reports on cereals under varied salinity stress levels. Lutts et al, (1996) reported decrease in total chlorophyll content in rice young and old leaves upon $\mathrm{NaCl}$ treatment. Cha-Um and Kirdmanee, 2009 suggested the decline in light and dark photosynthetic reactions were responsible for decrease in chlorophyll content in the maize cultivars (Table 1-10).

\section{Conditions}

Peroxidases are another important class of ROS scavenging enzymes whose level show significant elevation with increase in stress levels. The POX activity is also found higher in heat stressed Raj 4037 cultivar of wheat than the other wheat cultivars. Pusa Jai kisan cultivar of mustard and GNG-1581 cultivar of gram also outperform other cultivars of their species under consideration. POX is among the enzymes that scavenge $\mathrm{H}_{2} \mathrm{O}_{2}$ in chloroplasts, which is produced through dismutation of $\mathrm{O}^{2-}$ catalysed by SOD. The present study reported the rise in POX levels with increasing heat stress. Increased POX activities may also be attributed to increased activity of POX encoding genes (Boretal 2003). The higher POX values suggest more efficient $\mathrm{H}_{2} \mathrm{O}_{2}$ scavenging than the other plants at higher temperatures. 
APX uses ascorbate as the electron donor for the reduction of $\mathrm{H}_{2} \mathrm{O}_{2}$ and is well known to be important in the detoxification of $\mathrm{H}_{2} \mathrm{O}_{2}$. APX acts as strong catalyst together with MDHAR, DHAR and GR. The results of the present study are in good agreement with earlier observations which reported higher levels of APX in maize cultivars (Neto et al., 2006). Higher values of APX activities were observed for the variety Raj 3765 of wheat, Pusa Jai kisan of mustard and GNG-1581 of gram. A research group specifically addressed the enhancement in APX activities with rising salinity in rice varieties and reported that precise induction of APX 4 to 7 isoform is responsible for such behaviour (Lee et al., 2001).

Polyphenol oxidase enzyme activity was reported significantly higher in Raj 4037 heat stressed variety of wheat, Pusa Jai kisan and GNG-1581 of mustard and gram respectively. These levels also indicate better adaptability of the aforementioned cultivars of the plant species.
Many studies elucidated that the cell membrane is more sensitive to high temperature which results in damage of plant. Thylakoid membrane and the plasma membrane were more susceptible than the mitochondria to heat damage. Heat stress often leads to oxidative stress, eventually causing membrane peroxidation, protein structure damage and DNA injury. MDA was a product of lipid peroxidation which also effects membrane integrity Earlier studies (Han et al., 2013) has reported that with the rise in temperature, the MDA content has increased. Similar results were observed in our investigation where MDA contents enhanced constantly with exponential rise in temperature. The increased MDA content might be due to the membrane destruction resulting from ROS-induced oxidative damage. MDA is a by-product of lipid peroxidation and quantification of its endogenous levels is negatively correlated with the integrity of membranes (Arora, 2008).

Table.1 Morphological parameters of wheat varieties

\begin{tabular}{|l|c|c|c|c|c|}
\hline \multicolumn{1}{|c|}{ Varieties } & Lok - 1 & Raj 4120 & Raj 4037 & Raj 3765 & DBW - 90 \\
\hline Fresh weight(gm)- control & 1.426 & 1.179 & 1.19 & 1.167 & 0.115 \\
\hline Fresh weight(gm)- heat & 0.0742 & 0.101 & 0.123 & 0.087 & 0.037 \\
\hline Dry weight(gm)- control & 1.22 & 1.013 & 1.07 & 1.11 & 0.096 \\
\hline Dry weight(gm)- heat & 0.043 & 0.093 & 0.095 & 0.067 & 0.30 \\
\hline Shoot length(cm)- control & 15.6 & 9.67 & 10 & 9.6 & 7 \\
\hline Shoot length(cm)- heat & 6 & 4.67 & 6.33 & 3.33 & 4.5 \\
\hline Root length(cm)- control & 7.6 & 6.33 & 5.3 & 6.33 & 3.7 \\
\hline Root length(cm)- heat & 6 & 4.67 & 6.33 & 4.67 & 4.5 \\
\hline Germination efficiency (\%) & 100 & 100 & 100 & 100 & 100 \\
\hline
\end{tabular}


Table.2 Morphological parameters of Mung bean and soya bean varieties

\begin{tabular}{|l|c|c|}
\hline \multicolumn{1}{|c|}{ Varieties } & MUNG BEANIPM 02-03C/SI & SOYABEANJS-95-60 \\
\hline Fresh weight(gm)- control & 2.09 & 1.3 \\
\hline Fresh weight(gm)- heat & 1.74 & 1.38 \\
\hline Dry weight(gm)- control & 1.37 & 1.25 \\
\hline Dry weight(gm)- heat & 1.26 & 1.2 \\
\hline Shoot length(cm)- control & 14 & 9.0 \\
\hline Shoot length(cm)- heat & 5.3 & 2.33 \\
\hline Root length(cm)- control & 6.7 & 4 \\
\hline Root length(cm)- heat & 5.3 & 1.67 \\
\hline Germination efficiency $(\%)$ & 100 & 100 \\
\hline
\end{tabular}

Table.3 Morphological parameters of chickpea varieties

\begin{tabular}{|l|c|c|}
\hline \multicolumn{1}{|c|}{ Varieties } & Pratapchanna & GNG-1581 \\
\hline Fresh weight(gm)- control & 0.43 & 0.22 \\
\hline Fresh weight(gm)- heat & 0.22 & 0.18 \\
\hline Dry weight(gm)- control & 0.36 & 0.17 \\
\hline Dry weight(gm)- heat & 0.18 & 0.13 \\
\hline Shoot length(cm)- control & 4.5 & 6 \\
\hline Shoot length(cm)- heat & 1.5 & 4 \\
\hline Root length(cm)- control & 3.0 & 3 \\
\hline Root length(cm)- heat & 0.5 & 60 \\
\hline Germination efficiency $(\%)$ & 100 & \\
\hline
\end{tabular}

Table.4 Morphological parameters of mustard varieties

\begin{tabular}{|l|c|c|c|}
\hline \multicolumn{1}{|c|}{ Varieties } & RH-0749 & Pusa Jai kisan & Pusa Bold \\
\hline Fresh weight(gm)- control & 0.40 & 0.75 & 1.77 \\
\hline Fresh weight(gm)- heat & 0.05 & 0.06 & 0.07 \\
\hline Dry weight(gm)- control & 0.25 & 0.69 & 1.41 \\
\hline Dry weight(gm)- heat & 0.04 & 0.05 & 0.05 \\
\hline Shoot length(cm)- control & 8.7 & 8.37 & 9.0 \\
\hline Shoot length(cm)- heat & 1.5 & 1.08 & 1.67 \\
\hline Root length(cm)- control & 5.7 & 6.12 & 6.20 \\
\hline Root length(cm)- heat & 2.5 & 1.41 & 1.83 \\
\hline Germination efficiency $(\%)$ & 80 & 60 & 100 \\
\hline
\end{tabular}


Table.5 Biochemical parameters of crops for chlorophyll activity

\begin{tabular}{|l|c|l|c|r|r|r|}
\hline \multirow{2}{*}{ Parameters } & \multicolumn{3}{|c|}{ Wheat } & \multicolumn{1}{|c|}{ Soyabean } \\
\cline { 2 - 7 } & Lok-1 & DBW-90 & Raj-4120 & Raj-3765 & Raj-4037 & J5-95-60 \\
\hline Control & $20.4046 \pm 2$ & $18.0086 \pm 1.8$ & $20.4046 \pm 2.46$ & $21.5876 \pm 2.00$ & $22.1154 \pm 2.00$ & $13.1066 \pm 1.11$ \\
\hline Heat & $21.363 \pm 1.2$ & $20.3898 \pm 1.22$ & $16.7728 \pm 1.38$ & $17.3832 \pm 1.98$ & $22.4992 \pm 2.00$ & $14.5102 \pm 1.34$ \\
\hline
\end{tabular}

\begin{tabular}{|l|l|l|l|l|l|l|}
\hline \multirow{2}{*}{ Parameters } & \multicolumn{3}{|c|}{ Mustard } & \multicolumn{2}{c|}{ Mung } & \multicolumn{2}{c|}{ Gram } \\
\cline { 2 - 7 } & Pusa bold & RH-0749 & Pusa Jai kisan & IPM 02-3C/SI & GNG-1581 & Pratapchana \\
\hline Control & $16.9634 \pm 1.70$ & $17.3832 \pm 1.7$ & $18.121 \pm 1.81$ & $17.3068 \pm 1.73$ & $15.7548 \pm 1.5$ & $14.7456 \pm 1.44$ \\
\hline Heat & $15.9902 \pm 1.38$ & $17.6906 \pm 1.64$ & $17.214 \pm 1.39$ & $17.8136 \pm 1.38$ & $12.9942 \pm 1.58$ & $11.985 \pm 1.59$ \\
\hline
\end{tabular}

Table.6 Represents biochemical parameters of crops for peroxidises activity

\begin{tabular}{|l|c|l|l|r|r|r|}
\hline \multirow{2}{*}{ Parameters } & \multicolumn{3}{|c|}{ Wheat } & \multicolumn{2}{c|}{ Soyabean } \\
\cline { 2 - 7 } & Lok-1 & DBW-90 & Raj-4120 & Raj-3765 & Raj-4037 & J5-95-60 \\
\hline Control & $0.476 \pm 0.04$ & $1.344 \pm 0.13$ & $0.588 \pm 0.058$ & $0.588 \pm 0.045$ & $0.392 \pm 0.03$ & $0.196 \pm 0.016$ \\
\hline Heat & $1.204 \pm 0.12$ & $0.896 \pm 0.08$ & $1.26 \pm 0.16$ & $0.689 \pm 0.12$ & $1.54 \pm 0.038$ & $1.764 \pm 0.18$ \\
\hline
\end{tabular}

Table.7 Represents biochemical parameters of crops for Ascorbate peroxide

\begin{tabular}{|l|c|l|r|r|r|r|}
\hline \multirow{2}{*}{ Parameters } & \multicolumn{5}{|c|}{ Wheat } & Soyabean \\
\cline { 2 - 8 } & Lok-1 & DBW-90 & Raj-4120 & Raj-3765 & Raj-4037 & J5-95-60 \\
\hline Control & $0.0868 \pm 0.005$ & $0.1064 \pm 0.012$ & $1.176 \pm 0.034$ & $0.588 \pm 0.023$ & $1.456 \pm 0.05$ & $0.1372 \pm 0.007$ \\
\hline Heat & $0.1092 \pm 0.005$ & $0.1036 \pm 0.012$ & $0.1512 \pm 0.01$ & $0.2604 \pm 0.02$ & $0.1652 \pm 0.004$ & $0.3136 \pm 0.007$ \\
\hline
\end{tabular}

\begin{tabular}{|l|l|l|l|l|l|l|}
\hline \multirow{2}{*}{ Parameters } & Mustard & & & Mung & Gram & \\
& Pusa Bold & RH-0749 & Pusa jai kisan & JPM 0203C/SI & GNG-1581 & Pratapchana \\
\hline Control & $0.1148 \pm 0.002$ & $0.154 \pm 0.008$ & $0.1372 \pm 0.009$ & $0.0476 \pm 0.02$ & $0.07 \pm 0.008$ & $0.0476 \pm 0.009$ \\
\hline Heat & $0.0728 \pm 0.002$ & $0.1316 \pm 0.008$ & $0.2352 \pm 0.009$ & $0.0448 \pm 0.02$ & $0.09 \pm 0.008$ & $0.03 \pm 0.009$ \\
\hline
\end{tabular}


Table.8 Represents biochemical parameters of crops for poly phenol peroxidise (PPO) activity

\begin{tabular}{|l|r|l|l|l|l|l|}
\hline \multirow{2}{*}{ Parameters } & \multicolumn{5}{|c|}{ Wheat } & Soyabean \\
\cline { 2 - 8 } & Lok-1 & DBW-90 & Raj-4120 & Raj-3765 & Raj-4037 & J5-95-60 \\
\hline Control & $0.056 \pm 0.005$ & $0.112 \pm 0.012$ & $0.112 \pm 0.002$ & $0.028 \pm 0.004$ & $0.056 \pm 0.007$ & $0.084 \pm 0.002$ \\
\hline Heat & $0.056 \pm 0.005$ & $0.028 \pm 0.012$ & $0.056 \pm 0.002$ & $0.056 \pm 0.004$ & $0.112 \pm 0.007$ & $0.168 \pm 0.002$ \\
\hline
\end{tabular}

\begin{tabular}{|l|l|l|l|l|l|l|}
\hline \multirow{2}{*}{ Parameters } & \multicolumn{2}{|c|}{ Mustard } & \multicolumn{1}{c|}{ Mung } & \multicolumn{1}{c|}{ Gram } \\
\cline { 2 - 7 } & Pusa bold & RH-0749 & $\begin{array}{l}\text { Pusa Jai } \\
\text { kisan }\end{array}$ & $\begin{array}{l}\text { IPM 02-3 } \\
\text { C/SI }\end{array}$ & GNG-1581 & Pratap chana \\
\hline Control & $0.028 \pm 0.002$ & $0.056 \pm 0.008$ & $0.028 \pm 0.009$ & $0.224 \pm 0.02$ & $0.028 \pm 0.008$ & $0.028 \pm 0.009$ \\
\hline Heat & $0.084 \pm 0.002$ & $0.028 \pm 0.008$ & $0.084 \pm 0.009$ & $0.084 \pm 0.02$ & $0.056 \pm 0.008$ & $0.084 \pm 0.009$ \\
\hline
\end{tabular}

Table.9 Represents biochemical parameters of crops for MDA activity

\begin{tabular}{|l|r|l|l|l|l|l|}
\hline \multirow{2}{*}{ Parameters } & \multicolumn{5}{|c|}{ Wheat } & Soyabean \\
\cline { 2 - 8 } & Lok-1 & DBW-90 & Raj-4120 & Raj-3765 & Raj-4037 & J5-95-60 \\
\hline Control & $26.35 \pm 2.00$ & $74.4 \pm 1.8$ & $32.55 \pm 2.46$ & $32.55 \pm 2.00$ & $21.7 \pm 2.00$ & $10.85 \pm 1.11$ \\
\hline Heat & $66.65 \pm 1.2$ & $49.6 \pm 1.22$ & $69.75 \pm 1.38$ & $66.65 \pm 1.98$ & $20.15 \pm 2.00$ & $97.65 \pm 1.34$ \\
\hline
\end{tabular}

\begin{tabular}{|c|l|l|l|c|c|c|}
\hline \multirow{2}{*}{ Parameters } & \multicolumn{2}{|c}{ Mustard } & \multicolumn{3}{c|}{ Mung } & \multicolumn{2}{c|}{ Gram } & \\
\cline { 2 - 8 } & Pusa Bold & RH-0749 & Pusa jai kisan & JPM 0203C/SI & GNG-1581 & Pratap chana \\
\hline Control & $17.05 \pm 1.70$ & $7.75 \pm 1.7$ & $12.4 \pm 1.81$ & $7.75 \pm 1.73$ & $3.1 \pm 1.5$ & $1.55 \pm 1.44$ \\
\hline Heat & $24.8 \pm 1.38$ & $7.75 \pm 1.64$ & $55.8 \pm 1.39$ & $32.55 \pm 1.38$ & $4.65 \pm 1.58$ & $3.1 \pm 1.59$ \\
\hline
\end{tabular}

Table.10 Represents biochemical parameters of crops for Proline test

\begin{tabular}{|c|c|c|c|c|c|c|}
\hline \multirow[b]{2}{*}{ Parameters } & \multicolumn{5}{|l|}{ Wheat } & \multirow{2}{*}{$\begin{array}{l}\text { Soyabean } \\
\text { J5-95-60 }\end{array}$} \\
\hline & Lok-1 & DBW-90 & Raj-4120 & Raj-3765 & Raj-4037 & \\
\hline Control & $1.128 \pm 0.04$ & $1.8 \pm 0.13$ & $0.936 \pm 0.058$ & $0.744 \pm 0.045$ & $1.176 \pm 0.03$ & $1.56 \pm 0.016$ \\
\hline Heat & $2.016 \pm 0.12$ & $1.728 \pm 0.08$ & $1.44 \pm 0.16$ & $3.696 \pm 0.12$ & $2.424 \pm 0.038$ & $0.912 \pm 0.18$ \\
\hline \multirow[b]{2}{*}{ Parameters } & \multicolumn{3}{|c|}{ Mustard } & Mung & Gram & \\
\hline & Pusa bold & RH-0749 & $\begin{array}{l}\text { Pusa Jai } \\
\text { kisan }\end{array}$ & $\begin{array}{r}\text { IPM 02-3 } \\
\text { C/SI }\end{array}$ & GNG-1581 & Pratap chana \\
\hline Control & $2.856 \pm 0.028$ & $2.112 \pm 0.015$ & $3.336 \pm 0.025$ & $1.56 \pm 0.015$ & $0.792 \pm 0.009$ & $1.488 \pm 0.003$ \\
\hline Heat & $1.968 \pm 0.048$ & $1.368 \pm 0.015$ & $1.824 \pm 0.19$ & $1.008 \pm 0.046$ & $1.272 \pm 0.007$ & $2.424 \pm 0.004$ \\
\hline
\end{tabular}


Graph.1 Chlorophyll activity of different plant varieties under normal and stress

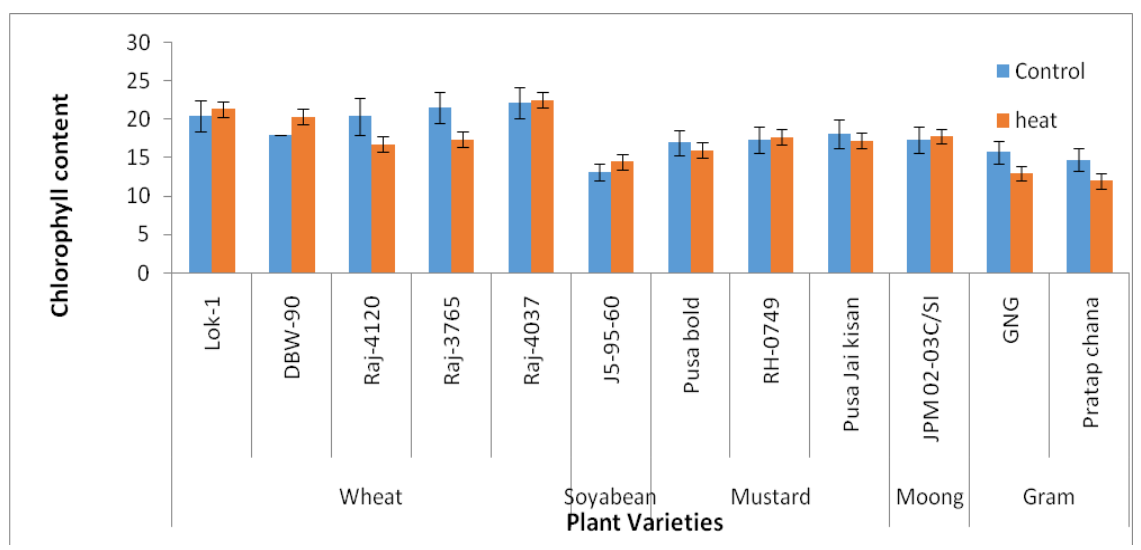

Graph.2 Peroxidase activity of different plant varieties under normal and stress conditions

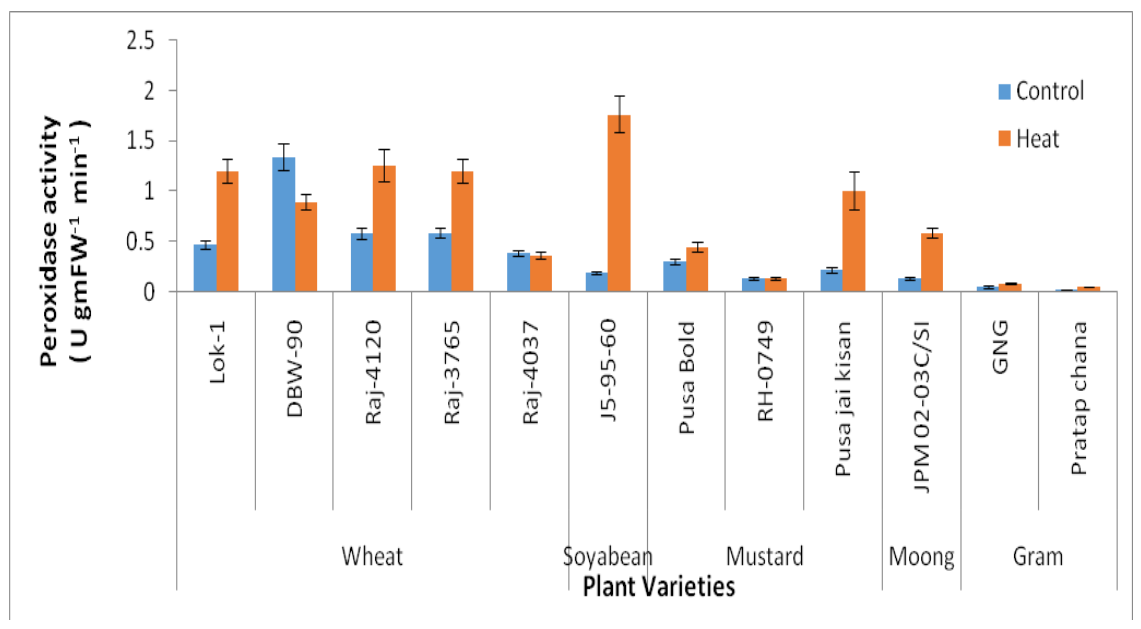

Graph.3 Ascorbate peroxide of different plant varieties under normal and stress conditions

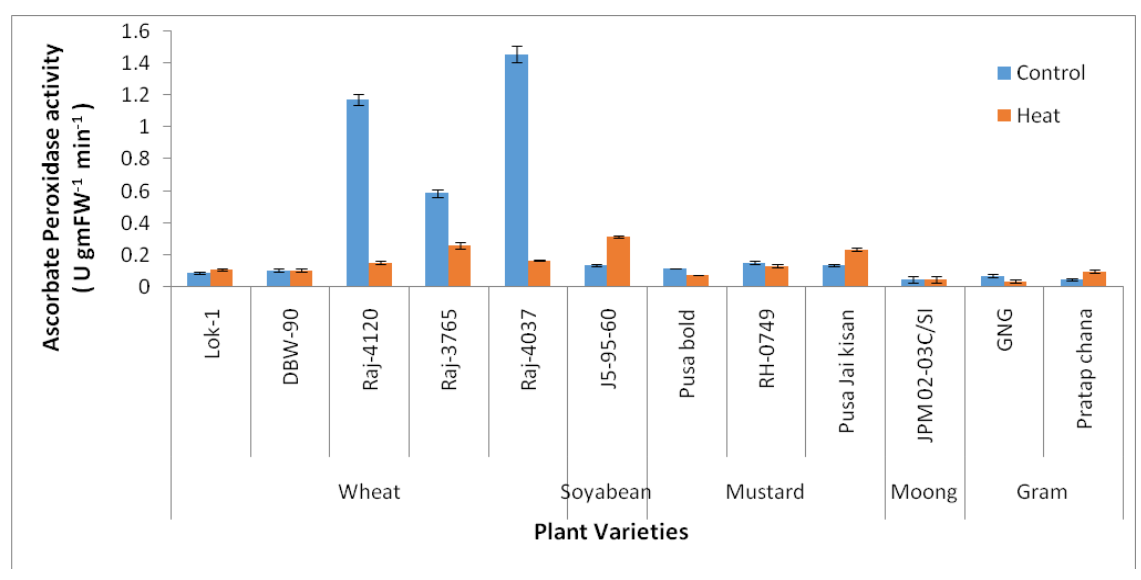


Graph.4 Poly phenol peroxidises (PPO) activity of different plant varieties under normal and stress conditions

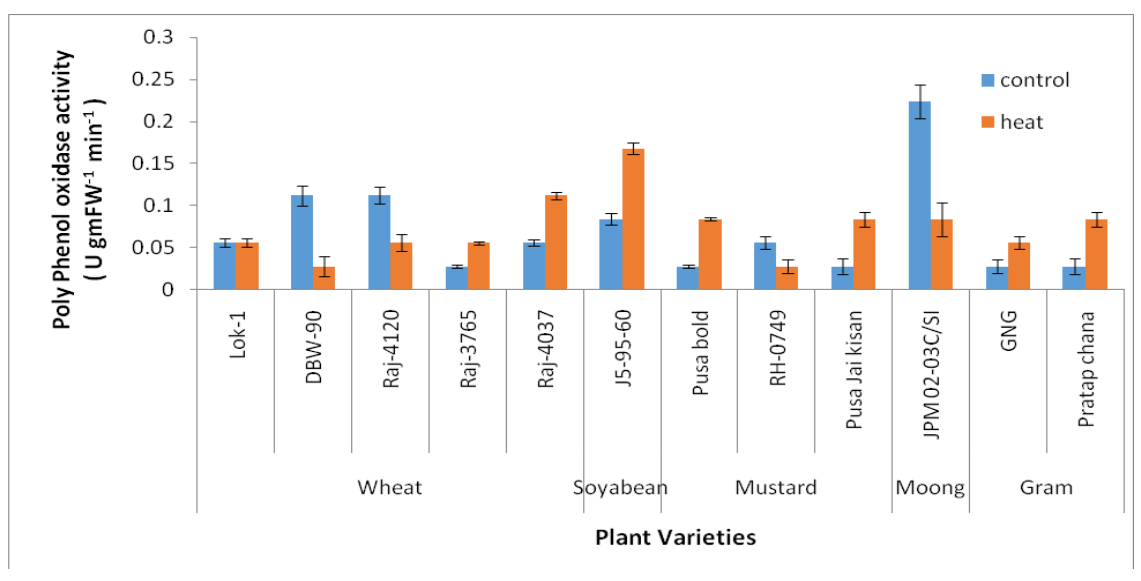

Graph.5 MDA activity of different plant varieties under normal and stress conditions

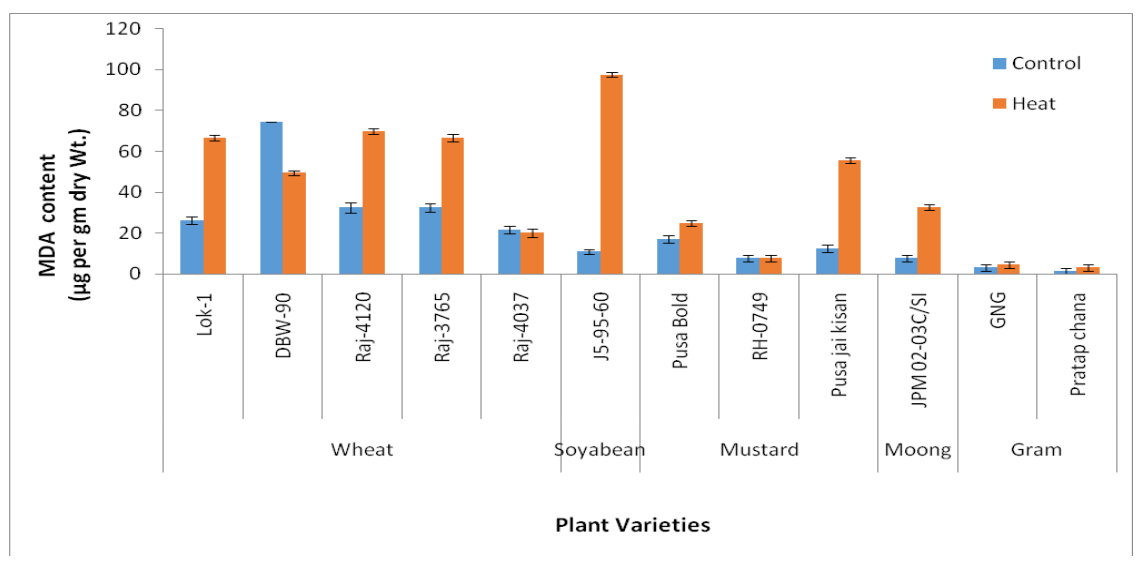

Graph.6 Proline test of different plant varieties under normal and stress conditions

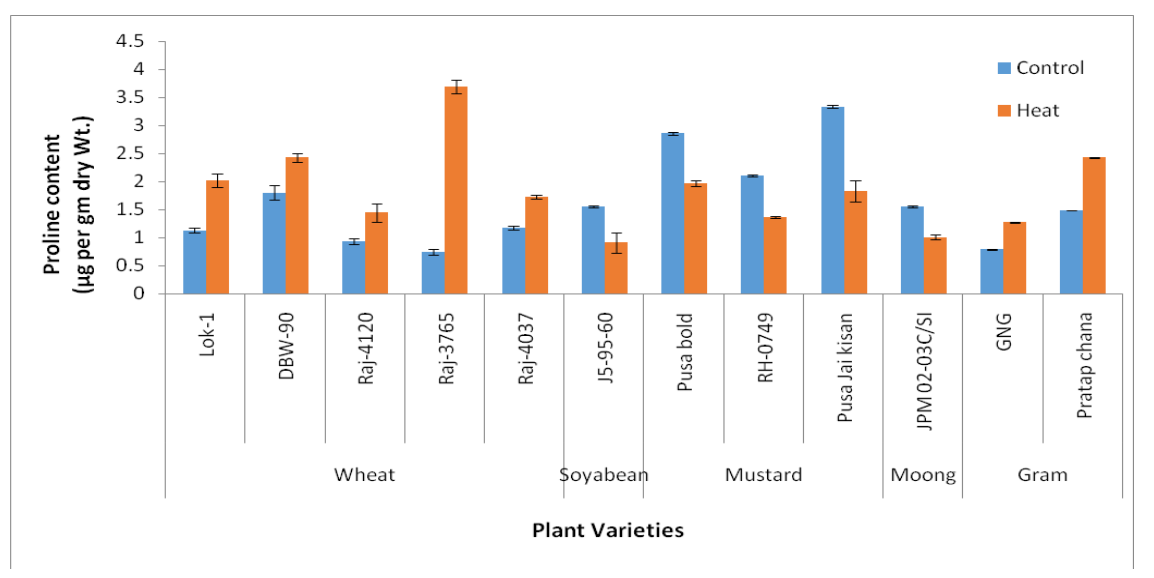


Proline functions as a kind of osmotic adjustment and under stress, the increase in Proline content proves beneficial in enhancing plant resistance to stress in a certain extent, thereby developing adaptations in organisms to survive under environmental stress. The proline content in Raj 3765 cultivar of wheat was the highest amongst all wheat varieties and slightly higher than Raj 4037 variety. Pusa bold and Pusa Jai Kisan of soyabean and mustard respectively also showed higher MDA contents in the present study. To overcome the effect of deficit of water, plants osmolytes such as proline are produced which act as low-molecular weight chaperones (Gupta et al., 2013). These osmolites stabilize and protect the structure of enzymes and proteins, maintain membrane integrity and scavenge reactive oxygen species (ROS). Due to its zwitter ion character, proline accumulates to high-concentration in cell cytoplasm. This higher level of proline content in leaves may be due to expression of genes encoding key enzymes of proline synthesis Pyrroline-5-carboxylate (P5C) and low activity of the oxidizing enzymes (proline dehydrogenase) which are controlled by osmotic and salinity stress. Finally, proline may act as a signaling/regulatory molecule able to activate multiple responses that aids in adaptation process (Izadi et al., 2014).

In conclusion, the study "Effect of heat stress on some domestic crop varieties of Rajasthan" was undertaken to establish the best performing variety under in vitro application of heat stress. In Rajasthan, the crops face a higher temperature range during their growing phase. The temperatures sometimes reach upto a remarkable value of $50^{\circ} \mathrm{C}$ too. With the growing intricacies of global warming, these prevailing conditions are about to worsen only. It will not only reduce the quantity but may also deteriorate the quality of the crops. Therefore, a pressing need exists for identifying the crop variety that performs exceptionally well under higher temperature exposure. Such varieties could be further taken up for quality improvement purposes too through the use of different plant breeding methods.

The present study was done to identify the best responding variety of different crops under higher temperatures. The seeds of the plants were sterilized and grown by inoculating on the MS medium. After initial germination, an in vitro heat stress was applied on the plant varieties by exposing them to higher temperatures for 5 hours a day continuously for 5 days. The plantlets were then excised from the medium and were taken up for different enzymatic assays. Five varieties of wheat, three of mustard and two varieties of gram were procured for the study. Following conclusions were drawn based on different biochemical parameters:

- The varieties Raj 4037 of wheat, Pusa Jai kisan (mustard) and GNG-1581 cultivar in gram were identified as best responding varieties in terms of chlorophyll content.

- Peroxidase enzyme activity was calculated and Raj 4037 cultivar of wheat, Pusa Jai kisan cultivar of mustard and GNG-1581 cultivar of gram were identified as better performers under stress.

- The polyphenol oxidase enzyme activity was calculated as highest in Raj 4037 cultivar of wheat, equivalent in Pusa bold and Pusa Jai Kisan of mustard and pratapchana of gram

- The calculations of ascorbate peroxidase enzyme activity revealed the following best responding varieties- Raj-3765 of wheat, Pusa Jai kisan of mustard and GNG-1581 of gram.

- Raj-3765 (wheat), Pusa Jai kisan (mustard) and GNG-1581 (gram) showed the highest MDA content under heat stress.

- The highest proline content under heat stress was observed in Raj-3765 cultivar of 
wheat, Pusa Bold of mustard respectively.

For the crops soyabean and mung, only one variety each was made available for the assays. Following conclusions were drawn for these crops:

- Chlorophyll content was reported higher in heat stressed plantlets.

- Peroxidase activity was significantly higher in both the heat stressed plantlets.

- PPO activity was significantly higher in soyabean but was reported less in heat stressed mung plantlets.

- APX activity was significantly higher in soyabean and non-significant in mung

- MDA content was reported significantly higher in both the crop species.

- Proline content was reported low in both the heat stressed plantlets.

The following varieties are recommended for growing under higher temperatures:

- Wheat- Raj-4037 (mainly) and Raj-3765, Mustard- Pusa Jai Kisan and Gram- GNG1581

- Amongst soybean and mung, Soybean in better adapted to grow under higher temperatures.

\section{References}

Arora N (2008) Effect of 28homobrassinolide on growth, lipid peroxidation and antioxidative enzyme activity in seedlings of Zea mays L. Under salinity stress. Acta Physiologiae Plantarum, 30.6: 833.

Azhar N, Hussain B, Ashraf MY and Abbasi KY (2011) Water stress mediated changes in growth, physiology and secondary metabolites of desiajwain (Trachyspermumammi L.) Pakistan Journal of Botany, 43: 15-9.

Azymi S, Sofalian O, Jahanbakhsh $G$ and Khomari S (2012) Effect of chilling stress on soluble protein, sugar and
Proline accumulation in cotto (Gossypi uhirsutum L.) genotypes. International Journal of Agriculture and Crop Sciences, 4: 825-30.

Boretal M, Ozdemir F and Turkan I (2003) The effect of salt stress on lipid peroxidation and antioxidants in leaves of sugar beet Beta vulgaris L. and wild beet Beta maritima L. Plant Science, 164: 77-84.

Cha-Um S and Kirdmanee C (2009) Effect of salt stress on Proline accumulation, photosynthetic ability and growth characters in two maize cultivars. Pakistan Journal of Botany, 41: 87-98.

Chinnusamy V, Jagendorf A and Zhu JK (2005) Understanding and improving salt tolerance in plants. Crop Science, 45: 437-448.

De Azevedo Neto AD, Prisco JT, Enéas-Filho $\mathrm{J}$, de Abreu CE and Gomes-Filho E (2006) Effect of salt stress on antioxidative enzymes and lipid peroxidation in leaves and roots of salt-tolerant and salt-sensitive maize genotypes. Environmental and Experimental Botany. 56: 87-94.

Gill SS and Tuteja N (2010) Reactive oxygen species and antioxidant machinery in abiotic stress tolerance in crop plants. Plant Physiology and Biochemistry, 48: 909-930.

Gupta SM, Pandey P, Negi PS, Pande V, Grover A, Patade VY and Ahmed Z (2013) DRE-binding transcription factor gene (LlaDREB1b) is regulated by various abiotic stresses in Lepidium latifolium L. Molecular Biology Reports, 40: 2573-2580.

Han Y, Fan S, Zhang Q and Wang Y (2013) Effect of heat stress on the MDA, Proline and soluble sugar content in leaf lettuce seedlings. Agricultural Sciences, 4: 112-115.

Haque MS, Kjaer KH, Rosenqvist E, Sharma DK and Ottosen CO (2014), Heat 
stress and recovery of photosystem II efficiency in wheat (Triticum aestivum L.) cultivars acclimated to different growth temperatures. Environmental and Experimental Botany, 99: 1-8.

Hasanuzzaman M, Nahar K, Alam MM, Roychowdhury R and Fujita M (2013) Physiological, biochemical, and molecular mechanisms of heat stress tolerance in plants. International Journal of Molecular Sciences, 14: 9643-9684.

Hasanuzzaman M, Nahar K, Fujita M (2013) Extreme Temperatures, Oxidative Stress and Antioxidant Defense in Plants. In Abiotic Stress-Plant Responses and Applications in Agriculture; Vahdati, K., Leslie, C., Eds.; InTech: Rijeka, Croatia, 169205.

Hatfield, J.L., Boote, K.J., Fay, P., Hahn, L., Izaurralde, R.C., Kimball, B.A., M Ader, T., Morgan, J., Ort, D., Polley, W., Thomson, A., Wolfe, D., 2008. Agriculture In:. The Effects of Climate Change on Agriculture, Land Resources, Water Resources, and Biodiversity in the United States.

Intergovernmental Panel Climate Change (IPCC), 2007. Climate Change 20 07: Impacts, Adaptation and Vulnerability: Contribution of Working Group II to the Fourth Assessment Report of the Intergovernmental Panel on Climate Change. Cambridge University Press, Cambridge, U.K. and New York, NY.

Izadi MH, Rabbani J, Emam Y, Pessarakli M and Tahmasebi A (2014) Effects of salinity stress on physiological performance of various wheat and barley cultivars. Journal of Plant Nutrition, 37: 520-523.

Johnson EJ (2002) The role of carotenoids in human health. Nutrition in Clinical Care, 5: 56-65.
Kao SC and Ganguly AR (2011) Intensity, duration, and frequency of precipitation extremes under 21 st- century warming scenarios. Journal of Geophysical Research: Atmospheres, 116.

Knight, H and Knight M.R (2001) Abiotic Stress signalling pathways: specificity and cross talk. Trends in plant science, 6(6) 262-267.

Lee D H, Kim Y S and Lee C B (2001) The inductive responses of the antioxidant enzymes by salt stress in the rice (Oryzasativa L.). Journal of Plant Physiology, 158: 737-745.

Lutts S, Kinet JM and Bouharmont J (1996) Effects of various salts and of mannitolon ion and Proline accumulation in relation to osmotic adjustment in rice (Oryza sativa L.) callus cultures. Journal of Plant Physiology, 149: 186-195.

Mittler R and Blumwald E (2010) Genetic engineering for modern agriculture: challenges and perspectives, Annual Review of Plant Biology, 61: 443-62.

Peleg Z and Blumwald E (2011) Hormone balance and abiotic stress tolerance in crop plants. Current Opinion in Plant Biology, 14: 290-295.

Polle A (2001) Dissecting the superoxide dismutase-ascorbate peroxidaseglutathione pathway in chloroplasts by metabolic modelling. Computer simulations as a step towards flux analysis. Plant Physiology, 126: 445462.

Potters G, Pasternak TP, Guisez Y and Jansen MA (2009) Different stresses, similar morphogenic responses: integrating a plethora of pathways. Plant, Cell \& Environment, 32: 158-69.

Potters G, Pasternak TP, Guisez Y, Palme KJ and Jansen MA (2007) Stress-induced morphogenic responses: growing out of trouble? Trends in Plant Science, 
12: $98-105$.

Ristic Z, Bukovnik U, Momcilovic I, Fu J and Rasad V (2008) Heat-induced accumulation of chloroplast protein synthesis elongation factor, $\mathrm{EF}-\mathrm{Tu}$, in winter wheat. Journal of Plant Physiology, 165: 192-202.

Ristic Z, Bukovnik U and Prasad PV (2007) Correlation between heat stability of thylakoid membranes and loss of chlorophyll in winter wheat under heat stress. Crop Science, 47: 2067-2073.
Talukder A, McDonald GK and Gill GS (2014) Effect of short-term heat stress prior to flowering and early grain set on the grain yield of wheat. Field Crops Research, 160: 54-63.

Zhang H, Han B, Wang T, Chen S, Li H, Zhang $Y$ and Dai S (2011) Mechanisms of plant salt response: insights from proteomics. Journal of Proteome Research, 11: 49-67.

\section{How to cite this article:}

Divya Sharma, Hrish Kumar Rachhoya, Mukesh Sharma and Ranjana Agarwal. 2018. Effect of Rising Temperature Stress on Growth and Physiology of Domestic Crops of Rajasthan, India. Int.J.Curr.Microbiol.App.Sci. 7(07): 1426-1440. doi: https://doi.org/10.20546/ijcmas.2018.707.170 